Pacific Journal of Mathematic 


\section{GENERALIZED FRATTINI SUBGROUPS OF FINITE GROUPS}

\section{J. C. Beidleman and T. K. Seo}

The purpose of this paper is to generalize some of the fundamental properties of the Frattini subgroup of a finite group. For this purpose we call a proper normal subgroup $H$ of $G$ a generalized Frattini subgroup if and only if $G=N_{G}(P)$ for each normal subgroup $L$ of $G$ and each Sylow $p$-subgroup $P, p$ is a prime, of $L$ such that $G=H N_{G}(P)$. Here $N_{G}(P)$ is the normalizer of $P$ in $G$. Among the generalized Frattini subgroups of a finite nonnilpotent group $G$ are the center, the Frattini subgroup, and the intersection $L(G)$ of all selfnormalizing maximal subgroups of $G$. The product of two generalized Frattini subgroups of a group $G$ need not be a generalized Frattini subgroup, hence $G$ may not have a unique maximal generalized Frattini subgroup.

Let $H$ be a generalized Frattini subgroup of $G$ and let $K$ be normal in $G$. If $K / H$ is nilpotent, then $K$ is nilpotent. Similarly, if the hypercommutator of $K$ is contained in $H$, then $K$ is nilpotent. We consider the Fitting subgroup $F(G)$ of a nonnilpotent group $G$, and prove $F(G)$ is a generalized Frattini subgroup of $G$ if and only if every solvable normal subgroup of $G$ is nilpotent.

Now let $H$ be a maximal generalized Frattini subgroup of a finite nonnilpotent group $G$. Following Bechtell we introduce the concept of an $H$-series for $G$ and prove that if $G$ possesses an $H$-series, then $H=L(G)$.

2. Notation The only groups considered here are finite.

If $H$ is a subgroup of a group $G$, then $H^{\prime}$ is the commutator (derived) subgroup of $H$,

$H^{(k)}(k>1)$ is the $k$-th commutator subgroup of $H$,

$H^{x}=x^{-1} H x$ for each $x \in G$,

$Z(H)$ is the center of $H$,

$Z^{*}(H)$ is the hypercenter of $H$ (i.e. the terminal member of the upper central series of $H), D(H)$ is the hypercommutator of $H$ (i.e. the terminal member of the lower central series of $H$ ),

$\phi(H)$ is the Frattini subgroup of $H$,

$F(H)$ is the Fitting subgroup of $H$ (i.e. the largest nilpotent normal subgroup of $H$ ),

$N_{G}(H)$ is the normalizer of $H$ in $G$.

If $H$ is a subset of a group $G$, then denote by $\langle H\rangle$ the subgroup of $G$ generated by $H$. 
In a group $G, L(G)$ is the intersection of the self-normalizing maximal subgroups of $G$ and $R(G)$ is the intersection of the normal maximal subgroups of $G$; in each case one sets $L(G)$ or $R(G)=G$ if the respective maximal subgroups do not exist properly (see [1]).

3. Generalized Frattini suhgroups. This section will be given to defining a generalized Frattini subgroup of a group and to the development of some properties of this type of subgroup.

Definition 3.1. A proper normal subgroup $H$ of a group $G$ is called a generalized Frattini subgroup of $G$ if and only if $G=N_{G}(P)$ for each normal subgroup $L$ of $G$ and each Sylow $p$-subgroup $P, p$ is a prime, of $L$ such that $G=H N_{G}(P)$.

We note that every proper normal subgroup of a nilpotent group $G$ is a generalized Frattini subgroup of $G$. This is not the case if $G$ is only supersolvable. For example, if $S_{3}$ is the symmetric group of three symbols, then the alternating subgroup $A_{3}$ is not a generalized Frattini subgroup.

THEOREM 3.1. Let $H$ be a generalized Frattini subgroup of a group $G$.

Then

(a) $H$ is nilpotent,

(b) A normal subgroup of $G$ contained in $H$ is a generalized Frattini subgroup of $G$,

(c) $H \phi(G)$ is a generalized Frattini subgroup of $G$,

(d) $H Z(G)$ is a generalized Frattini subgroup of $G$, whenever it is a proper subgroup.

Proof. (a) Let $P$ be a Sylow $p$-subgroup of $H$ where $p$ is a fixed prime. Because of Theorem 6.2.4 of [4], $G=H N_{G}(P)$, hence $G=N_{G}(P)$. Since all the Sylow subgroups of $H$ are normal, $H$ is nilpotent.

(b) Let $K$ be a normal subgroup of $G$ contained in $H, L$ a normal subgroup of $G$, and $P$ a Sylow $p$-subgroup, $p$ is a prime, of $L$ such that $G=K N_{G}(P)$. Then $G=H N_{G}(P)$, hence $G=N_{G}(P)$.

(c) This is an immediate consequence of Theorem 7.3.8 of [4].

(d) Since $Z(G)$ is contained in the normalizer of every subgroup of $G, H Z(G)$ is a generalized Frattini subgroup of $G$.

We now note that the intersection of generalized Frattini subgroups of a group $G$ is a generalized Frattini subgroup of $G$. However, this is not true in general when we consider products of subgroups (see Example 3.3).

As a consequence of Theorem 3.1 we have the following.

COROLlaRY 3.1.1 The Frattini subgroup of $G$ is a generalized 
Frattini subgroup of $G$. Moreover, if $G$ is nonabelian, then $Z(G)$ is a generalized Frattini subgroup of $G$.

The following result is a generalization of Theorem 7.4 .8 of [4].

THEOREM 3.2. Let $H$ be a generalized Frattini subgroup of $G$. If $K$ is a normal subgroup of $G$ and $K / H$ is nilpotent, then $K$ is nilpotent.

Proof. Let $K$ be a normal subgroup of $G$ such that $K / H$ is nilpotent. Let $P$ be a Sylow $p$-subgroup of $K$ for a fixed prime $p$. Then $H P / H$ is a Sylow $p$-subgroup of $K / H$, hence $H P / H$ is a characteristic subgroup of $K / H$. Therefore, $H P / H$ is normal in $G / H$, and so $H P$ is normal in $G$. Since $P$ is a Sylow $p$-subgroup of $H P, G=$ $(H P) N_{G}(P)$ because of Theorem 6.2.4 of [4]. Hence $G=H N_{G}(P)$, which implies $G=N_{G}(P)$. Since all the Sylow subgroups of $K$ are normal, $K$ is nilpotent.

Let $H$ be a generalized Frattini subgroup of $G$. Then by Theorem 3.1 $F(G)$ contains $H$. From Theorem 3.2 $F(G / H)=F(G) / H$, hence we obtain the following corollaries.

CoRollary 3.2.1. If $H$ is a generalized Frattini subgroup of $G$, then $F(G / H)=F(G) / H$.

CoRollary 3.2.2. Let $H$ be a generalized Frattini subgroup of $G$. Then $G$ is nilpotent if and only if $G / H$ is nilpotent

CoRollary 3.2.3. A group $G$ is nilpotent if and only if its commutator subgroup $G^{\prime}$ is a generalized Frattini subgroup of $G$.

The next result is similar to Theorem 2.3 of [1], however it generalizes Bechtell's result.

THEOREM 3.3. Let $H$ be a generalized Frattini subgroup of $G$. If $K$ is a normal subgroup of $G$ whose hypercommutator $D(K)$ is contained in $H$, then $D(K)=1$ and $K$ is nilpotent.

Proof. From Theorem 3.1 it follows that $D(K)$ is a generalized Frattini subgroup of $G$. Since $K / D(K)$ is nilpotent, $K$ is nilpotent by Theorem 3.2 , hence $D(K)=1$.

CoRollary 3.3.1. A proper normal subgroup $K$ of a group $G$ is nilpotent if and only if its commutator subgroup $K^{\prime}$ is a generalized Frattini subgroup of $G$. 
Proof. By Theorem 7.3.17 of [4], $\phi(K) \subseteq \phi(G)$. Hence the corollary follows from Theorem 7.3.5 of [4], Corollary 3.1.1 and Theorem 3.3 .

Our next objective of this section is to show that $L(G)$ is a generalized Frattini subgroup of $G$ whenever $G$ is nonnilpotent. We begin with the following theorem.

THEOREM 3.4. Let $H$ be a generalized Frattini subgroup of $G$ and let $K$ be a proper normal subgroup of $G$ containing $H$. Then $K / H$ is a generalized Frattini subgroup of $G / H$ if and only if $K$ is a generalized Frattini subgroup of $G$.

Proof. Assume that $K$ is a generalized Frattini subgroup of $G$. Let $L / H$ be a normal subgroup of $G / H$ and let $P$ be a Sylow $p$-subgroup, $p$ is a prime, of $L$ such that $G / H=(K / H) N_{G / H}(H P / H)$. Then $G=$ $K N_{G}(H P)$. Let $g=k x$, where $k \in K$ and $x \in N_{G}(H P)$. Then $P^{x} \subseteq H P$. Since $L$ is a normal subgroup of $G, P^{x}$ and $P$ are Sylow $p$-subgroups of $L \cap H P$. Therefore, there is an element $y$ of $L \cap H P$ such that $P^{x y}=P$, hence $x y$ is an element of $N_{G}(P)$. Therefore $g y=k(x y)$ is contained in $K N_{G}(P)$. Since $K N_{G}(P)$ contains $H P$, it follows that $y$ is an element of $K N_{G}(P)$, and therefore $g \in K N_{G}(P)$. This shows that $G=K N_{G}(P)$, and hence $G=N_{G}(P)$ since $K$ is a generalized Frattini subgroup of $G$. From this we conclude that $H P / H$ is normal in $G / H$, and so $K / H$ is a generalized Frattini subgroup of $G / H$.

Conversely, assume that $K / H$ is a generalized Frattini subgroup of $G / H$. Let $L$ be a normal subgroup of $G$ and let $P$ be a Sylow $p$-subgroup, $p$ is a prime, of $L$ such that $G=K N_{G}(P)$. Then $G / H=$ $(K / H) N_{G / H}(H P / H)$, hence $N_{G / H}(H P / H)=G / H$ since $H P / H$ is a Sylow $p$-subgroup of $H L / H$ and $H L / H$ is normal in $G / H$. Therefore, $H P$ is a normal subgroup of $G$. Let $P_{1}$ be a Sylow $p$-subgroup of $H P$ which contains $P$. By Theorem 6.2.4 of [4], $G=(H P) N_{G}\left(P_{1}\right)=H N_{G}\left(P_{1}\right)$, hence $G=N_{G}\left(P_{1}\right)$ since $H$ is a generalized Frattini subgroup of $G$. From this it follows that the Fitting subgroup $F(G)$ of $G$ contains $P$, hence $K P$ is a nilpotent subgroup because of Theorems 3.1 and 3.2. Since $G=K N_{G}(P)$, it follows that $K P$ is a normal nilpotent subgroup of $G$.

We now show $N_{G}(P)$ contains $K P$. For let $P_{2}$ be a Sylow $p$ subgroup of $K P$. Then $P_{2}$ is normal in $G$, hence $P \subseteq P_{2}$. Let $P_{3}$ be a Sylow $p$-subgroup of $G$ containing $P_{2}$. Since $L$ is normal in $G$, $L \cap P_{3}=P$ and $N_{G}\left(P_{3}\right) \subseteq N_{G}(P)$. From this it follows that $P_{2} \subseteq N_{G}(P)$. Hence $K P \subseteq N_{G}(P)$, since $K P$ is nilpotent. This shows $G=N_{G}(P)$, and therefore $K$ is a generalized Frattini subgroup of $G$.

Because of Corollary 3.1.1, Theorem 2.2 of [1] and Theorem 3.4, 
we obtain the following theorem.

THEOREM 3.5. If $L(G)$ is a proper subgroup of $G$, then $L(G)$ is a generalized Frattini subgroup of $G$.

We now give several examples that will help illustrate the theory of this section.

EXAMPLE 3.1. Let $Q=\left\langle a, b \mid a^{4}=1, a^{2}=b^{2}, b a=a^{-1} b\right\rangle$ and let $G$ be the direct product of $Q$ and $S_{3}$, the symmetric group on three symbols. Then $\phi(G)=Z(G)=\left\langle a^{2}\right\rangle, L(G)=Q$ and $F(G)=Q \times A_{3}$. $F(G)$ is not a generalized Frattini subgroup of $G$. We note that $L(G)$ properly contains $\phi(G)$.

EXAMPLE 3.2. Let $H=\langle h\rangle$ be a cyclic group of order 49 and let $G$ be the direct product of $H$ and $S_{5}$, where $S_{5}$ is the symmetric group on five symbols. Then $\phi(G)=\left\langle h^{7}\right\rangle$ and $F(G)=L(G)=Z(G)=H$. Hence $F(G)$ is a generalized Frattini subgroup of $G$ which properly contains $\phi(G)$.

Our examples indicate that the Fitting subgroup of a group $G$ need not be a generalized Frattini subgroup of $G$. However, the next two theorems provide a necessary and sufficient condition for $F(G)$ to be a generalized Frattini subgroup of $G$.

THEOREM 3.6. If the Fitting subgroup $F(G)$ of $G$ is a generalized Frattini subgroup of $G$, then every solvable normal subgroup of $G$ is nilpotent.

Proof. Let $H$ be a solvable normal subgroup of $G$ and let $k$ be the smallest positive integer such that $H^{(k+1)}=1$. Then $F(G)$ contains $H^{(k)}$, hence by Theorem $3.1 H^{(k)}$ is a generalized Frattini subgroup. Since $H^{(k-1)} / H^{(k)}$ is abelian, $H^{(k-1)}$ is nilpotent by Theorem 3.2. Hence $F(G)$ contains $H^{(k-1)}$. Proceeding in this way we can prove $H^{\prime} \leqq F(G)$, hence $H^{\prime}$ is a generalized Frattini subgroup of $G$ by Theorem 3.1. By applying Theorem 3.2, we see that $H$ is nilpotent.

As a consequence of Theorem 3.6 we have the following.

COROLlaRY 3.6.1. If $F(G)$ is a generalized Frattini subgroup of $G$, then $G$ can not be solvable.

Definition 3.2. For a group $G$ denote by $S(G)$ the radical of $G$ (i.e. the unique maximal solvable normal subgroup of $G$ ).

THEOREM 3.7. Let $G$ be a nonnilpotent group. If $S(G)=F(G)$, 
then $F(G)$ is a generalized Frattini subgroup of $G$.

Proof. Let $H$ be a normal subgroup of $G$ and let $P$ be a Sylow $p$-subgroup of $H, p$ is a fixed prime, such that $G=F(G) N_{G}(P)$. Then $F(G) P / F(G)$ is a solvable normal subgroup of $G / F(G)$, hence $F(G) P$, is a solvable normal subgroup of $G$. Since $F(G)$ is the radical of $G$, $F(G)$ contains $P$. Hence $P$ is a Sylow $p$-subgroup of $H \cap F(G)$. Since $H \cap F(G)$ is a nilpotent normal subgroup, $P$ is normal in $G$. Therefore, $F(G)$ is a generalized Frattini subgroup of $G$.

From Theorems 3.6 and 3.7 we have the following.

THeOREM 3.8. Let $G$ be a nonnilpotent group. The Fitting subgroup of $G$ is a generalized Frattini subgroup of $G$ if and only if it is the radical of $G$.

From Theorem 3.8 and the fact that a solvable subnormal subgroup of a group $G$ is contained in the radical of $G$ we obtain the following result.

THEOREM 3.9. If the Fitting subgroup of a group $G$ is a generalized Frattini subgroup of $G$, then every solvable subnormal subgroup of $G$ is nilpotent.

A generalized Frattini subgroup of a group $G$ is called maximal if it is not properly contained in any other generalized Frattini subgroup of $G$. We now consider maximal generalized Frattini subgroups of a group $G$.

Let $H$ be a maximal generalized Frattini subgroup of $G$. Then $H$ contains $\phi(G)$ by Theorem 3.1. Now suppose that $L(G)$ is a proper subgroup (i.e. $G$ is nonnilpotent). By Theorem 2.2 of [1] $L(G) / \phi(G)=$ $Z(G / \phi(G))$, hence $H$ contains $L(G)$ by Theorems 3.1 and 3.4 . We have proved the following.

THEOREM 3.10. A maximal generalized Frattini subgroup of a nonnilpotent group $G$ contains $L(G)$.

CoRollary 3.10.1 A maximal generalized Frattini subgroup of a nonnilpotent group $G$ contains the hypercenter of $G$.

Proof. It is sufficient to apply Theorem 2.2 of [1] and Theorem 3.10 .

We conclude this section with an example which illustrates several properties of generalized Frattini subgroups. 
EXAMPLE 3.3. Let $G$ be a group of order 84 with the following properties:

(a) $G$ has 28 Sylow 3-subgroups,

(b) $G$ has a normal Sylow 7-subgroup $H$,

(c) $G$ has a normal Sylow 2-subgroup $K$ which is isomorphic to the Klein four-group.

We note that such a group exists (see 9.2.14 of [4]).

Then $H$ and $K$ are generalized Frattini subgroups of $G$, however $F(G)=H K$ is not a generalized Frattini subgroup. We also note that both $H$ and $K$ are maximal generalized Frattini subgroups of $G$. Hence a maximal generalized Frattini subgroup need not be unique. Finally, $L(G)=\phi(G)=Z(G)=1$, and therefore a maximal generalized Frattini subgroup may contain the intersection of the self-normalizing maximal subgroups properly.

4. Small subgroups. This section is devoted to the study of generalized Frattini subgroups which are small in a group $G$.

DEFINITION 4.1 A proper normal subgroup $H$ of a group $G$ is said to be small in $G$ if and only if $G=K$ for each other normal subgroup $K$ of $G$ such that $G=H K$ (see [2]).

Let $H$ be a small subgroup of $G$ which is contained in $L(G)$. Suppose $R(G)$ does not contain $H$. Then there exists a normal maximal subgroup $B$ such that $G=H B$, which implies $G=B$. Hence $R(G)$ contains $H$, and therefore $\phi(G)$ must contain $H$. We have established the following two results.

THEOREM 4.1. Let $H$ be a proper normal subgroup of $G$ which is contained in $L(G)$. If $H$ is small in $G$, then $\phi(G)$ contains $H$.

THEOREM 4.2. If $L(G)$ is small in $G$, then $L(G)=\phi(G)$.

We note that Example 3.1 shows that the assumption that $L(G)$ is small in Theorem 4.2 is needed.

Since the center of a group $G$ is contained in $L(G)$, we obtain the following result from Theorem 4.1.

THEOREM 4.3. If the center $Z(G)$ is small in $G$, then $Z(G)$ is contained in $\phi(G)$.

Let $H$ be a generalized Frattini subgroup of $G$. Suppose that $H$ is small in $G$ and every proper normal subgroup of $G / H$ is nilpotent. Let $K$ be a proper normal subgroup of $G$. Then $H K$ is also a proper normal subgroup of $G$. Hence $H K / H$ is nilpotent, and so $H K$ is 
nilpotent by Theorem 3.2. Therefore $K$ is nilpotent. We have proved the theorem which follows.

THEOREM 4.4. Let $H$ be a generalized Frattini subgroup of $G$ which is small in $G$. If every proper normal subgroup of $G / H$ is nilpotent, then every proper normal subgroup of $G$ is nilpotent.

Since an extention of a solvable group by a solvable group is solvable, we obtain the following result from Theorem 4.4 and Corollary 3.6.1.

CoROLLARY 4.4.1. Let $G^{\prime}$ be a proper subgroup of $G$ and let $H$ be a generalized Frattini subgroup of $G$. If $H$ is small in $G$ and every proper normal subgroup of $G / H$ is nilpotent, then $G$ is solvable and $F(G)$ is not a generalized Frattini subgroup of $G$.

We note that in Corollary 4.4.1 it is necessary to assume $G^{\prime}$ is a proper subgroup of $G$. For we need only to consider the alternating group on five symbols.

5. $H$-series. Let $H$ be a (fixed) maximal generalized Frattini subgroup of $G$. In this section we define an $H$-series for $G$ and develop some of its elementary properties. We note that part of this section is closely related to Bechtell's results on $L$-series in [1].

Definition 5.1. Let $H$ be a maximal generalized Frattini subgroup. Then

(a) an $H$-series for $G$ is a series

$$
H=B_{0} \supseteqq B_{1} \supseteq B_{2} \supseteqq \cdots \supseteqq B_{j} \supseteq \cdots
$$

such that $B_{i}$ is normal in $G$ and $B_{i} / B_{i+1} \subseteq Z\left(G / B_{i+1}\right)$ for $i=0,1,2, \cdots$,

(b) the upper $H$-series is a series

$$
H=H_{0} \supseteqq H_{1} \supseteqq \cdots \supseteqq H_{j} \supseteqq \cdots
$$

in which $\left[H_{i-1}, G\right]=H_{i}$, for $i=1,2, \cdots$, and

(c) the lower $H$-series is a series

$$
1=Z_{0} \subseteq Z_{1} \subseteq \cdots Z_{j} \subseteq \cdots
$$

in which $Z_{j} / Z_{j-1}=Z\left(G / Z_{j-1}\right)$, for $j=1,2, \cdots$, (i.e. the lower $H$-series for $G$ is the upper central series in the sense of Scott [4]).

REMARK 5.1. If one replaces $H$ by $L(G)$ in the above definition, then we obtain the concepts of $L$-series, upper $L$-series and lower $L$ series given by Betchell [1]. However, we mention that $L(G)$ need not be a maximal generalized Frattini subgroup. 
Let $H$ be a maximal generalized Frattini subgroup of $G$. Then we say that $G$ possesses an $H$-series if there exists an $H$-series for $G$ which terminates with the identity subgroup.

REMARK 5.2. A group $G$ is said to possess an $L$-series if it has an $L$-series which terminates with the identity subgroup (see [1]).

From Theorem 6.4.1 of [4] we have the following.

THEOREM 5.1. Let $H$ be a maximal generalized Frattini subgroup of $G$. If $G$ possesses an $H$-series $H=B_{0} \supseteqq B_{1} \supseteqq \cdots \supseteqq B_{k}=1$, then $B_{j} \supseteqq H_{j}, \quad$ for $j=0,1,2, \cdots, \quad k$, and $H_{k-j} \leqq B_{k-j} \leqq Z_{j}$, for $j=$ $0,1,2, \cdots, k$.

Now let $H$ be a maximal generalized Frattini subgroup of nonnilpotent group $G$. By Theorem 3.10 and Theorem 2.2 of [1], it follows that $H \supseteqq L(G) \supseteqq Z^{*}(G)$. Hence, if $G$ possesses an $H$-series, then $H=$ $L(G)=Z^{*}(G)$ by Theorem 5.1. We have established the following.

THEOREM 5.2. Let $H$ be a maximal generalized Frattini subgroup of a nonnilpotent group $G$. If $G$ possesses an $H$-series, then $H=$ $L(G)=Z^{*}(G)$.

The fact that $G$ possesses an $H$-series in Theorem 5.2 cannot be omitted.

EXAmPle 5.1. Let $G$ be the group of order 84 presented in Example 3.3 and let $N$ be a cyclic group of order 5 . Let $M$ be the direct product of $G$ and $N$. Then $\phi(M)=1$ and therefore $L(M)=$ $Z(M)=N$. We also note that $H$ and $K$ generalized Frattini subgroups of $M$, however $H Z(M)$ and $K Z(M)$ are maximal generalized Frattini subgroups of $M$ which properly contain $L(M)=Z(M)$. Now let $W=$ $H Z(M)$. Then $M$ does not possess a $W$-series and $W \neq L(M)$. However, since $L(M)=Z(M), G$ possesses an $L$-series by Corollary 3.1.1 of $[1]$.

The converse of Theorem 5.2 is not true in general.

EXAMPLE 5.2. Let $G=\left\langle a, b \mid a^{9}=b^{2}=b a b a=1\right\rangle$. Then $F(G)=\langle a\rangle$, $L(G)=\dot{\phi}(G)=\left\langle a^{3}\right\rangle$, and $Z^{*}(G)=Z(G)=1$. However, $L(G)$ is a maximal generalized Frattini subgroup of $G$.

We conclude this section with two corollaries to Theorem 5.2.

CoRollary 5.2.1. Let $F(G)$ be a generalized Frattini subgroup 
of $G$. If $G$ possesses an $F(G)$-series, then $F(G)=L(G)=Z^{*}(G)$.

Proof. In this case $F(G)$ is a maximal generalized Frattini subgroup, hence the corollary follows from Theorem 5.2.

From Corollary 5.2.1 and Theorem 4.2 we have the following.

CoRollary 5.2.2. Let $F(G)$ be a generalized Frattini subgroup of $G$. If $F(G)$ is small in $G$ and $G$ possesses an $F(G)$-series, then $F(G)=\phi(G)$.

6. Remarks, In [3] Huppert proved the following theorem: A finite group $G$ is supersolvable if and only if $F / \phi(G)$ is supersolvable. Hence one might raise the following question: If $H$ is a generalized Frattini subgroup of $G$ and $G / H$ is supersolvable, then is $G$ supersolvable? The answer to this question is no in general. For let $G$ be the group of order 84 given in Example 3.3 and let $H$ be the Sylow 2-subgroup of $G$. Then $H$ is a generalized Frattini subgroup and $G / H$ is supersolvable. However, $G$ is not supersolvable.

We mention that one can prove the following using results of Huppert [3]. If $L(G)$ is a proper subgroup of $G$ and $G / L(G)$ is supersolvable, then $G$ is supersolvable.

In a later paper the authors will study those groups for which Huppert's result is true whenever generalized Frattini subgroups are considered instead of the Frattini subgroup.

\section{REFERENCES}

1. H. F. Bechtell, Pseudo-Frattini subgroups, Pacific J. Math. 14 (1964), 1129-1136.

2. J. C. Beidleman, A radical for near-ring modules, Michigan Math. J. 12 (1965), 377-383.

3. B. Huppert, Normalteiler und maximale Untergruppen endlicher Gruppen, Math. Zeit. 60 (1954), 409-434.

4. W. R. Scott, Group Theory, Prentice-Hall, New Jersey, 1964.

Received February 21, 1967. The research of the first author was supported by N.S.F. Grant G.P. 5948. The research of the second author was supported by the University of Kentucky Research Foundation.

UNIVERSITY OF KENTUCKY

LEXINGTON, KentUCKY 


\section{PACIFIC JOURNAL OF MATHEMATICS}

\section{H. ROYDEN}

Stanford University

Stanford, California

\author{
J. P. JANS \\ University of Washington \\ Seattle, Washington 98105
}

\section{EDITORS}

\author{
J. DugundJI \\ Department of Mathematics \\ Rice University \\ Houston, Texas 77001 \\ Richard ARENS \\ University of California \\ Los Angeles, California 90024
}

\section{ASSOCIATE EDITORS}
E. F. BECKENBACH
B. H. NeumanN
F. WOLF
K. YOSIDA

\section{SUPPORTING INSTITUTIONS}

\author{
UNIVERSITY OF BRITISH COLUMBIA \\ CALIFORNIA INSTITUTE OF TECHNOLOGY \\ UNIVERSITY OF CALIFORNIA \\ MONTANA STATE UNIVERSITY \\ UNIVERSITY OF NEVADA \\ NEW MEXICO STATE UNIVERSITY \\ OREGON STATE UNIVERSITY \\ UNIVERSITY OF OREGON \\ OSAKA UNIVERSITY \\ UNIVERSITY OF SOUTHERN CALIFORNIA
}

\author{
STANFORD UNIVERSITY \\ UNIVERSITY OF TOKYO \\ UNIVERSITY OF UTAH \\ WASHINGTON STATE UNIVERSITY \\ UNIVERSITY OF WASHINGTON \\ AMERICAN MATHEMATICAL SOCIETY \\ CHEVRON RESEARCH CORPORATION \\ TRW SYSTEMS \\ NAVAL ORDNANCE TEST STATION
}

Mathematical papers intended for publication in the Pacific Journal of Mathematics should be typewritten (double spaced). The first paragraph or two must be capable of being used separately as a synopsis of the entire paper. It should not contain references to the bibliography. Manuscripts may be sent to any one of the four editors. All other communications to the editors should be addressed to the managing editor, Richard Arens at the University of California, Los Angeles, California 90024.

50 reprints per author of each article are furnished free of charge; additional copies may be obtained at cost in multiples of 50 .

The Pacific Journal of Mathematics is published monthly. Effective with Volume 16 the price per volume (3 numbers) is $\$ 8.00$; single issues, $\$ 3.00$. Special price for current issues to individual faculty members of supporting institutions and to individual members of the American Mathematical Society: $\$ 4.00$ per volume; single issues $\$ 1.50$. Back numbers are available.

Subscriptions, orders for back numbers, and changes of address should be sent to Pacific Journal of Mathematics, 103 Highland Boulevard, Berkeley 8, California.

Printed at Kokusai Bunken Insatsusha (International Academic Printing Co., Ltd.), 7-17, Fujimi 2-chome, Chiyoda-ku, Tokyo, Japan.

PUBLISHED BY PACIFIC JOURNAL OF MATHEMATICS, A NON-PROFIT CORPORATION

The Supporting Institutions listed above contribute to the cost of publication of this Journal, but they are not owners or publishers and have no responsibility for its content or policies. 


\section{Pacific Journal of Mathematics}

A. A. Aucoin, Diophantine systems ............................. 419

Charles Ballantine, Products of positive definite matrices. I ............... 427

David Wilmot Barnette, A necessary condition for d-polyhedrality ............ 435

James Clark Beidleman and Tae Kun Seo, Generalized Frattini subgroups of finite groups ......................................... 441

Carlos Jorge Do Rego Borges, A study of multivalued functions ............. 451

William Edwin Clark, Algebras of global dimension one with a finite ideal

lattice ...............................................

Richard Brian Darst, On a theorem of Nikodym with applications to weak convergence and von Neumann algebras .........................

George Wesley Day, Superatomic Boolean algebras .....................

Lawrence Fearnley, Characterization of the continuous images of all

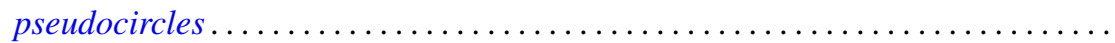

Neil Robert Gray, Unstable points in the hyperspace of connected subsets....... 515

Franklin Haimo, Polynomials in central endomorphisms .................. 521

John Sollion Hsia, Integral equivalence of vectors over local modular lattices . . . . 527

Jim Humphreys, Existence of Levi factors in certain algebraic groups .......... 543

E. Christopher Lance, Automorphisms of postliminal $C^{*}$-algebras ............ 547

Sibe Mardesic, Images of ordered compacta are locally peripherally metric . . . . 557

Albert W. Marshall, David William Walkup and Roger Jean-Baptiste Robert Wets,

Order-preserving functions: Applications to majorization and order

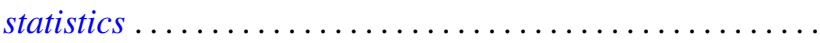

Wellington Ham Ow, An extremal length criterion for the parabolicity of

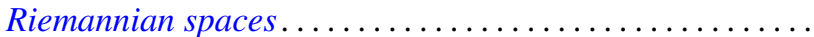

585

Wellington Ham Ow, Criteria for zero capacity of ideal boundary components of

Riemannian spaces...................................... 591

J. H. Reed, Inverse limits of indecomposable continua .................. 597

Joseph Gail Stampfli, Minimal range theorems for operators with thin spectra . . . 601

Roy Westwick, Transformations on tensor spaces..................... 613

Howard Henry Wicke, The regular open continuous images of complete metric

spaces ........................................... 621

Abraham Zaks, A note on semi-primary hereditary rings .............. 627

Thomas William Hungerford, Correction to: "A description of $\operatorname{Mult}_{i}\left(A^{1}, \cdots, A^{n}\right)$

by generators and relations" ............................. 629

Uppuluri V. Ramamohana Rao, Correction to: "On a stronger version of Wallis' formula".............................................. 629

Takesi Isiwata, Correction: "Mappings and spaces" ................... 630

Henry B. Mann, Josephine Mitchell and Lowell Schoenfeld, Correction to:

"Properties of differential forms in $n$ real variables" .... . .

James Calvert, Correction to: "An integral inequality with applications to the

Dirichlet problem"............................. 